\title{
The Hippocampus and Nucleus Accumbens as Potential Therapeutic Targets for Neurosurgical Intervention in Schizophrenia
}

\author{
Charles B. Mikell Guy M. McKhann Solomon Segal Robert A. McGovern \\ Matthew B. Wallenstein Holly Moore \\ Department of Neurological Surgery, Columbia University, New York, N.Y., USA
}

\section{Key Words}

Deep brain stimulation - Schizophrenia $\cdot$ Neurostimulation . Hippocampus $\cdot$ Nucleus accumbens $\cdot$ Dopamine $\cdot$ Psychosis

\begin{abstract}
Schizophrenia is a chronic and disabling psychiatric illness that is often refractory to treatment. Psychotic symptoms (e.g. hallucinations and delusions) in schizophrenia are reliably correlated with excess dopamine levels in the striatum, and have more recently been related to excess metabolic activity in the hippocampus. Multiple lines of evidence suggest that aberrantly high hippocampal activity may, via hippocampal connections with the limbic basal ganglia, drive excessive dopamine release into the striatum. In the present paper, we hypothesize that inhibition or stabilization of neural activity with high-frequency electrical stimulation of the hippocampus or nucleus accumbens, through different mechanisms, would treat the positive symptoms of schizophrenia. Thus, we suggest a direction for further experimentation aimed at developing neurosurgical therapeutic approaches for this devastating disease.
\end{abstract}

Copyright $\odot 2009$ S. Karger AG, Basel

\section{Introduction}

Schizophrenia is a chronic and disabling medical illness that affects approximately $0.7 \%$ of the population [1]. The symptoms associated with schizophrenia are divided into three domains: 'positive symptoms', which include disorders of thought and perception of reality, including delusions and hallucinations, 'negative symptoms', including social withdrawal and avolition, and 'cognitive symptoms', including impairments in attention, memory and executive function. Figure 1 shows these symptom domains, their proposed pathophysiology, and current treatment strategies. In the present article, we propose a novel surgical treatment of the positive symptoms of schizophrenia, based on current models of the neurocircuitry of psychosis. We hypothesize that chronic, highfrequency electrical stimulation (HFS) of the hippocampus or the nucleus accumbens (NAc), through stabilization of dopamine (DA) release in the striatum, may improve positive symptoms in patients with schizophrenia.

\section{The Clinical Features and Current Treatment of}

Schizophrenia

The positive, or psychotic, symptoms of schizophrenia are the most distinctive features of the disease. Psychosis

\section{KARGER \\ Fax +4161306 1234 E-Mail karger@karger.ch} www.karger.com
Holly Moore, $\mathrm{PhD}$

Columbia University, Department of Psychiatry

1051 Riverside Dr., Mail Unit 14

New York, NY 10032 (USA)

Tel. +1 212543 6938, Fax +1 212543 1017, E-Mail hm2035@columbia.edu 
Fig. 1. Schizophrenia has positive, negative, and cognitive symptom domains.

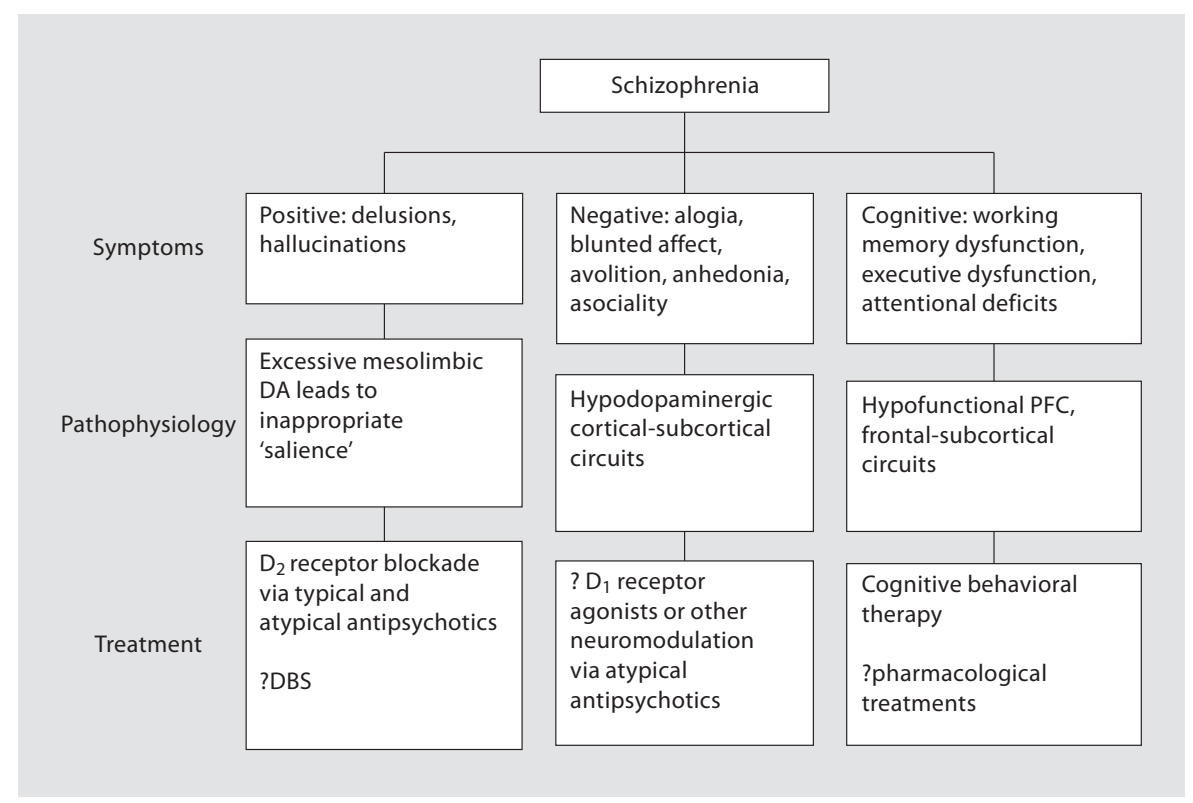

is a failure of reality testing, usually characterized by delusions and auditory hallucinations. Delusions are fixed, false ideas about the world, often paranoid in content, but may also involve convictions of being controlled by a power outside of oneself. They are often accompanied by auditory hallucinations, perceived sounds that are not actually present [2]. Positive symptoms of schizophrenia are treated primarily with antipsychotic pharmacotherapy.

All currently approved antipsychotic agents antagonize receptors in the $\mathrm{D}_{2}$ dopamine receptor family (including $\mathrm{D}_{2}, \mathrm{D}_{3}$, and/or $\mathrm{D}_{4}$ receptors) [3; for a recent review, see 4]. The 'typical' antipsychotics have relatively higher specificity and/or affinity for the $\mathrm{D}_{2}$ receptor family; newer 'atypical' antipsychotics exhibit receptor binding profiles that also include affinities for serotonin, acetylcholine and $\alpha$-adrenergic receptors [5]. These medications primarily treat the positive symptoms of schizophrenia, although newer atypical agents may ameliorate, or at least not exacerbate, negative symptoms as well [57]. The clinical efficacy of antidopaminergic medication is consistent with the hypothesis that excessive striatal DA mediates psychosis. This hypothesis has since been more directly supported by positron emission tomography (PET) imaging studies showing that both basal levels of DA and amphetamine-induced DA release are significantly increased in the striatum in patients with schizophrenia, and also related DA levels to positive symptoms or response of those symptoms to treatment [8-12].
Kapur [13] has hypothesized that schizophrenia is a disorder of dopaminergically mediated salience. In this model, DA codes for the 'incentive salience' of sensory stimuli (including internal stimuli). Excessive and untimely DA release may contribute to a dysregulation of neural circuits that, in turn, leads the patient to perceive voices, sounds, and images as 'inappropriately salient'. The patient thus assigns false significance to stimuli or events, and forms associations among such stimuli and events that are not predictive of or relevant to actual events likely to be encountered by the patient. These false associations are experienced by the patient as delusions. In the case of auditory hallucinations, internal thoughts are assigned special salience when experienced concurrently with inappropriate DA release. The patient then perceives these thoughts as external stimuli or 'voices in my head'. The patient's attempts to make sense of hallucinations within a cognitive structure or belief system can also contribute to the formation and tenacity of delusions.

Blockade of DA receptors can ameliorate positive symptoms. Although the neural circuit changes contributing to this effect have not been fully elucidated, one often cited hypothesis is that antipsychotics cause a 'depolarization block' of midbrain DA neurons leading to a decrease in DA levels in the striatum [14, 15]. Although this hypothesis has recently been challenged [16], most studies of the effects of antipsychotic drugs on striatal DA release show that chronic administration of these drugs 
results in decreased extracellular levels of DA in the striatum, related to decreased presynaptic DA synthesis, and/or a decrease in the responsivity of DA efflux to pharmacological triggers $[17,18]$.

Despite advances in antipsychotic pharmacology (but see Keefe et al. [19]), schizophrenia remains a life-altering diagnosis that requires lifelong medication and therapy. Moreover, the lifelong treatment that patients must endure can have significantly debilitating side effects, and does not always adequately control their symptoms [20]. Approximately one third to one fifth of patients with schizophrenia do not fully respond to medication. Of these, a portion of patients have psychotic symptoms refractory to multiple medication trials. Depending on the criteria used, there are 200,000-500,000 patients with treatment-resistant schizophrenia in the United States alone [21]. Treatment resistance correlates with suicide in schizophrenia, which claims the life of $5 \%$ of affected patients $[22,23]$. Even among patients in whom the medications are efficacious, side effects make lifelong compliance onerous. Typical antipsychotics, such as haloperidol and thioridazine, cause dose-dependent parkinsonian motor side effects (extrapyramidal side effects) as a consequence of DA receptor antagonism. On the other hand, olanzapine, the most popularly prescribed atypical antipsychotic, while not associated with extrapyramidal side effects, causes significant weight gain, as well as diabetes and associated complications of obesity [24]. Moreover, antipsychotic medications are simply unpleasant to take. This syndrome has been termed neuroleptic dysphoria, and a recent PET study suggests that $\mathrm{D}_{2}$ inhibition correlates with both therapeutic benefit and subjective dysphoria [25]. Given this Faustian bargain, novel therapeutic approaches are desperately needed.

In the present paper, we present a strategy for employing HFS of specific hippocampal or striatal subregions as an adjunct or alternative to pharmacotherapy for psychosis and possibly other symptom domains in schizophrenia. In fact, our approach is not new; Monroe and Heath [26] report improved social functioning and affect in a small number of patients with schizophrenia after being treated with 'septal' stimulation (e.g. NAc). Since that time, there has been great advancement in the use of deep brain stimulation (DBS), the application of HFS to specific gray or white matter regions in the brain. DBS emerged in the 21st century as an experimental treatment for multiple refractory psychiatric syndromes, including depression, obsessive-compulsive disorder (OCD), and Tourette's syndrome (reviewed by Ressler and Mayberg [27], Nuttin et al. [28], Mayberg et al. [29], Rauch et al. [30], Greenberg et al. [31],
Maciunas et al. [32], and Welter et al. [33]). Although psychiatry has a long history of the use of neurosurgical procedures (primarily lesions), HFS of specific brain regions offers the theoretical advantage of being either a stimulatory or an inhibitory procedure, depending on the anatomic localization and the settings used. Though efficacy data for most psychiatric DBS interventions remain highly preliminary, randomized DBS trials have begun enrollment for OCD and depression (effectiveness of DBS for treating people with treatment-resistant OCD: Clinicaltrials.gov NCT00640133; DBS for treatment-refractory major depression: Clinicaltrials.gov NCT00122031). All of this has proceeded cautiously, with careful ethical consultations and multidisciplinary cooperation, given the history of psychosurgery in the United States [34].

Deriving a Rational Basis for Neurostimulation-Based Therapy for Schizophrenia: Neurocircuitry, Current Models and Outstanding Questions

The dysregulation of DAergic pathways in psychosis has been well established. As described above, pharmacologic inhibition of the $\mathrm{D}_{2}$ receptor has been shown to successfully treat and control the positive symptoms of schizophrenia. Likewise, agents that act to increase the concentration of DA at the synaptic cleft, such as amphetamine, acutely worsen psychosis. More recent neurochemical (SPECT or PET) imaging studies have confirmed that the exacerbation of psychosis by amphetamine is related to the ability of the drug to increase extracellular DA concentrations in the striatum [8]. Moreover, basal DA (as assessed by measuring baseline occupancy of $\mathrm{D}_{2}$ family receptors by endogenous $\mathrm{DA}$ ) predicts patients' response to antipsychotic medication [10]. Robust evidence of DAergic involvement in schizophrenia suggests two related questions: (1) how does excessive DA lead to positive symptoms, and (2) how does excessive release of phasic DA happen?

To answer these questions, scientists have examined the normal functions of DA in the striatum. The midbrain DA system is conventionally divided into two pathways: the mesolimbic system, and the nigrostriatal system. Although the conceptualization of these systems with regard to their differential involvement in psychosis in schizophrenia is changing [35], for the purposes of this paper we will define the nigrostriatal system as DA innervation of the motor regions of the striatum by central and lateral divisions of the substantia nigra pars compacta and the mesolimbic system as inputs to the medial caudate and entire NAc from the ventral tegmental area (VTA) and medial substantia nigra DA neurons. The ni- 
grostriatal pathway is responsible for motor planning and motor initiation, and it is notably deficient in Parkinson disease, which is characterized by degeneration of the substantia nigra pars compacta. The mesolimbic pathway is important for reward-based associative learning, as well as calculations of behavioral salience, utility, and willingness to exert effort (see Schultz [36] for a thorough discussion of DA in associative learning; for a different view, see Salamone et al. [37]). It is the mesolimbic pathway that has been presumed to be involved in schizophrenia, although dysfunction in the mesolimbic pathway likely leads to disruption in DA function throughout the striatum. Both of these systems are likely activated by reward or in anticipation of selecting a response directed at a predictor or reward. A classic primate experiment by Hollerman and Schultz [38] demonstrated that DA neurons are activated by unexpected reward and inhibited by withholding of reward. These activations are said to be 'phasic', in contrast to the more constant 'tonic' release of DA (reviewed in Goto et al. [39]).

The tonic/phasic hypothesis of DA release proposes that midbrain neurons release DA in two different modes [40]. Tonic DA is determined by continual pacemakerlike firing of DA neurons that leads to nanomolar levels of DA concentration at baseline, which is transiently increased by phasic burst firing of DA neurons. Phasic activation acutely elevates DA to levels as high as millimolar for very brief periods (reviewed in Goto and Grace [41]). Tonic and phasic DA release are thought to have distinct functions. Tonic DA modulates frontal/striatal interactions important for goal-directed behavior. It also activates inhibitory presynaptic $\mathrm{D}_{2}$ receptors which limit DA release. Phasic activation, by contrast, is critical for reward-based learning and the assigning of incentive salience to sensory stimuli, a mechanism which is proposed to be disrupted in the previously described model of Kapur [13]. Recent studies suggest that hippocampal activation may drive phasic DA release when the hippocampus detects novelty, and possibly in other settings [42, 43].

\section{The Hyperactive Hippocampus in Schizophrenia}

Both patient and animal model data suggest that hippocampal dysfunction may contribute to aberrant DA release in schizophrenia. Under normal circumstances, activation of the hippocampus increases the proportion of spontaneously active DA neurons in the VTA [44]. Between phasic activations, a significant proportion of VTA DA neurons are not firing, because they are tonically inhibited by GABAergic projections from the ventral palli- dum (VP). Activation of the ventral hippocampus in the rodent (analogous to the anteromedial hippocampus of the human) is postulated to activate GABAergic neurons in the NAc that, in turn, inhibit GABAergic neurons in the VP that project to and normally inhibit VTA neurons. One net effect of hippocampal activation is to release DA neurons in the VTA from inhibition by the VP, thus, allowing for phasic activation by glutamatergic projections to the VTA.

Given the hypothesized role of the hippocampus in regulating striatal, particularly mesolimbic, DA release, this region may be a valid target for HFS-mediated inactivation for the treatment of psychosis in schizophrenia. In schizophrenia, there is robust evidence for hippocampal dysfunction. In particular, hippocampal volume loss has been replicated across numerous studies. Two metaanalyses $[45,46]$ and one large recent cohort from Australia [47] have confirmed that the hippocampus is smaller in patients with schizophrenia by approximately $5 \%$. These studies do not address whether volume loss is itself pathogenic, or is secondary to the effects of chronic hyperactivity on the sensitive hippocampus. However, recent functional imaging studies have suggested a pathogenic role for hippocampal abnormalities. SPECT, PET and fMRI studies have all pointed to abnormalities in the hippocampus in schizophrenia. Broadly speaking, imaging studies suggest hypometabolism of the hippocampus in patients relative to controls (reviewed in Gothelf et al. [48]). Yet upon closer examination, these studies do not reveal baseline hypoactivity as much as failure to recruit the hippocampus in memory tasks where hippocampal activation is typically robust. This is consistent with a model in which activation is constitutive. More recently, using a cohort of first-episode psychosis patients, the deficit in hippocampal activation was shown to be relatively specific to the encoding of semantic 'relatedness' (whether images were related in content or not), arguing against a general inability to recruit the hippocampus [49]. However, cerebrovascular-based measures of activation such as BOLD and rCBF are illsuited to detect chronic hyperactivity of the hippocampus, the condition suggested by excessive phasic DA release.

Chronic hyperactivity would be expected to produce atrophy and a lower rCBF over time, as is the case in temporal lobe epilepsy (TLE); Lahti et al. [50] have recently shown a negative correlation between the severity of positive symptoms and hippocampal $\mathrm{rCBF}$ in patients who have suffered chronically ( $>10$ years) from the disorder. The situation is similar in TLE. In TLE, a long literature 
reports chronically low blood flow and decreased cerebral metabolism using SPECT, PET, and fMRI, with marked increases during seizures (reviewed in Duncan [51]). Hypometabolism is most pronounced when the hippocampus is sclerotic and atrophied [52]. Hence, although the hippocampus does not appear overtly sclerotic in postmortem studies of schizophrenia, it is not implausible that excitotoxicity occurring within this region early in the course of the disorder may contribute to both the decrease in metabolic activity and postmortem histopathology associated with chronic schizophrenia.

Data from animal models and prodromal patients are most consistent with a model of early hyperactivation with subsequent excitotoxicity, followed by volume loss over time. In a recent MRI study of prodromal patients, increased $\mathrm{rCBF}$ strongly predicted an imminent psychotic break [53]. These findings are consistent with hippocampal hyperactivity in schizophrenia, especially in the early stage of the disorder which features more positive symptomatology. Similarly, in the MAM-E17 rat model of schizophrenia [54], silencing the hippocampus with tetrodotoxin normalized the rat's locomotor response to amphetamine [55], a behavioral response that depends on DA inputs to the NAc. Thus hippocampal hyperactivity may drive aberrant DA release in the striatum and contribute to psychosis. Therefore we propose that HFS of the hippocampus in schizophrenia patients, particularly the anteromedial region which is analogous to the caudal ventral hippocampus of the rat, may prevent excessive DA release in the striatum and ameliorate positive symptoms.

\section{HFS of the Hippocampus Is Inhibitory}

HFS of the hippocampus has been used to control seizures in patients with refractory TLE [56-59]. The effects of HFS in the hippocampus have also been modeled extensively in animals [60-63]. In patients, the target has typically been the anterior hippocampus [57], and reductions in seizure frequency from 30 to $100 \%$ have been reported $[58,59]$. While the precise mechanism is unclear, hippocampal HFS leads to a general reduction in excitability, as measured by reduction in interictal spikes [58] and decreased perfusion by SPECT [56]. Patients are typically unaware of hippocampal HFS, making blinded studies possible. Importantly, minimal side effects have been reported with HFS of the hippocampus; neuropsychological testing scores improved (perhaps due to improved seizure control) in the cohort of Velasco et al. [59]. This suggests that hippocampal HFS is a safe, effective way to decrease the output of the hyperexcitable hippocampus.

\section{Striatal Control of Midbrain DA Release:}

A Surgical Target

The striatum has three major functional subdivisions: the sensorimotor striatum, the ventral striatum (VS, including the NAc), and the associative striatum (AST) (reviewed in Joel and Weiner [64]). In addition to the role of the NAc in regulating DA release in response to hippocampal activation, the entire striatum is a major input to the midbrain DA system and plays a major role in regulating DA release [65]. On anatomic grounds, Haber et al. [65] and Ikemoto [66] have proposed a 'spiral' of both reciprocal and feed-forward projections from the striatum to the DAergic midbrain, which constitutes a mechanism for routing information through successive parts of the striatum. This postulated cognitive circuit begins in the VS where judgments about value are made, continues to the AST where information about context is provided, and terminates on the sensorimotor striatum where motor plans are formulated. At each step, DA output to the striatum is inhibited or stimulated by specific striatonigrostriatal projections.

Recent studies have suggested that there may be distinct patterns of DA dysregulation within the functional subdivisions of the striatum in schizophrenia. While antipsychotic response correlates to $\mathrm{D}_{2}$ receptor occupancy in the VS [12], a recent PET study using $\alpha$-methyl-paratyrosine depletion of DA has suggested that the 'hotspot' of DA release in schizophrenia is the AST [35]. The AST has extensive connections with the dorsolateral prefrontal cortex, an area subserving cognitive processes known to be deficient in schizophrenia, including working memory [67]. $\mathrm{D}_{2}$ overexpression in the striatum has been shown to recapitulate dorsolateral prefrontal cortex-like deficits in a mouse model [68], suggesting that excessive DA release in the AST may contribute to both positive and negative symptoms in schizophrenia.

The mechanisms regulating DA release into the striatum are not fully understood, but the posited striatonigrostriatal circuit of Haber et al. [65] may be a major contributor. In their model, each successive part of the striatum controls DA release from the midbrain into the next part, via GABAergic projections from striatal neurons onto DA neurons in the midbrain. In this way, the VS controls DA release into the AST, and the AST controls DA release into the sensorimotor striatum. The output of the striatum to the midbrain has both a reciprocal and nonreciprocal component. The reciprocal component is a projection onto DA neurons that project directly back to the same striatal neurons, while the nonreciprocal component projects to the DA neurons that innervate the next 
part of the striatum. The authors propose that the reciprocal projection of the VS is to the same DA neurons in the VTA that innervate the VS. The authors suggest that the nonreciprocal component projects onto inhibitory interneurons in the densocellular substantia nigra pars compacta, a region that releases DA into the AST. In this manner, activation of the VS inhibits DA release into itself, and stimulates DA release into the AST. We propose that this interaction is a possible surgical target in schizophrenia.

\section{HFS of the NAc Partially Activates and Stabilizes DA}

\section{Transmission}

HFS of the NAc and closely related structures has been used therapeutically in a variety of settings, including OCD [31, 69], Tourette's syndrome [70], and major depressive disorder [71, 72]. In rodents, NAc HFS has been shown to decrease cocaine-seeking behavior in cocainehabituated animals [73] and to attenuate morphine reinforcement [74]. From the variety of clinical effects produced by NAc HFS, it has become clear that the 'reversible functional lesion' paradigm [75] is not appropriate to NAc HFS. More consistent with the therapeutic effects of NAc DBS is a model in which HFS partially activates and stabilizes DA transmission in the NAc.

We propose that HFS raises tonic DA levels in the NAc (perhaps by directly depolarizing VTA axon terminals) and simultaneously inhibits phasic surges in DA, in a manner similar to the effects of the $\mathrm{D}_{2}$ partial agonist aripiprazole [76]. Stimulation of the NAc causes a rapid and reversible improvement in mood in many patients [71, 72], an effect likely mediated by a local increase in tonic DA. Such an increase in tonic DA in the NAc/VS may mediate the antidepressant effects of Brodmann area 25 stimulation [Segal and Moore, in preparation]. Increases in tonic DA stimulation are known to inhibit phasic DA release $[77,78]$. Thus, HFS of the NAc may partially activate and stabilize DA transmission in the NAc. Stabilization of DA transmission in the NAc by increased tonic DA may have an effect on DA release in the AST, given the 'spiraling' anatomy of the striatonigrostriatal circuit proposed by Haber et al. [65].

\section{The Hypothesis}

Proposed Targets in Schizophrenia:

Hippocampus and NAc (fig. 2)

Hippocampal Stimulation: Rationale

There are two major arguments for stimulating the hippocampus:

Hippocampal/Nucleus Accumbens

Surgery for Schizophrenia
(1) There is robust evidence for hippocampal involvement in schizophrenia. As described above, current evidence supports hippocampal hyperactivity early in the course of the illness. Excessive activation likely leads to excessive DA release, and the exacerbation of positive symptoms. Stimulation may damp down this excessive activation, just as it does in TLE.

(2) Inactivation of the hippocampus blocked the behavioral phenotype associated with aberrant DA release in a rodent model of schizophrenia.

For these reasons, we suggest that chronic stimulation of the hippocampus may ameliorate the positive symptoms of schizophrenia.

NAc Stimulation: Rationale

Additionally, we propose the NAc as a target, for the following reasons:

(1) The NAc is required for the release of DA from the midbrain in response to hippocampal activation [79]. This suggests that NAc stimulation may interrupt this circuit, and have effects comparable to hippocampal stimulation.

(2) The NAc controls DA release both in itself and in the AST, both regions involved in psychosis. Neurosurgical experience stimulating the NAc is consistent with partial activation and stabilization of DA release in the NAc. We propose that this stabilization will be therapeutic in schizophrenia.

These observations suggest that stimulation of the hippocampus or NAc may be suited to control the DAergic system in psychosis. We acknowledge that the effects of hippocampus/NAc stimulation in patients with schizophrenia are unknown. While there is long neurosurgical experience with stimulation of both of these regions, all previous studies of NAc stimulation have scrupulously avoided patients with histories of psychosis, due to concerns over psychotic exacerbation from depolarizing axon terminals in the VS. There is a single case report of NAc stimulation in a patient with OCD and residual psychotic symptoms, which reported no exacerbation of psychosis [80].

\section{Alternate Approaches}

Based on current neurocircuitry models of schizophrenia, several other targets are possible. These include the VP (globus pallidus internus) and the VTA.

Ventral Pallidum

The VP controls the number of VTA neurons under tonic inhibition, thereby setting the tonic level of DA, and

Stereotact Funct Neurosurg 2009;87:256-265 
Fig. 2. Multiple lines of evidence suggest the hippcampal input to the NAc is hyperactive in schizophrenia, leading to excessive DA release from the VTA into the NAc. The subiculum of the hippocampus and the NAc both may represent surgical targets for the interruption of this circuit. $\mathrm{Hc}=$ Hippocampus. From Martin [84] with kind permission.

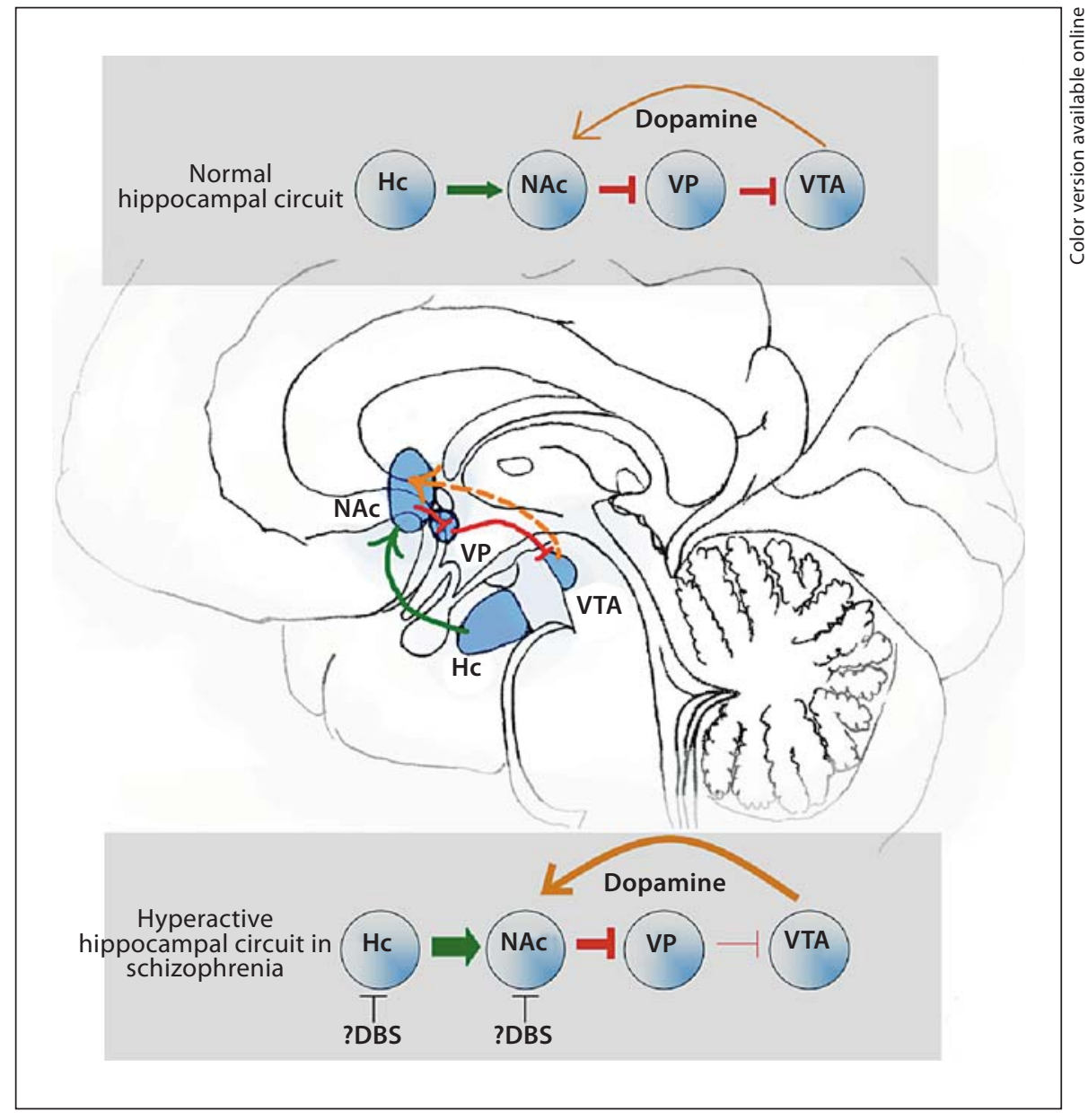

determining the number of neurons that can be activated via phasic stimulation. Therefore, inhibiting the VP would be expected to increase both tonic and phasic DA levels [44]. Although there is surgical experience stimulating the VP for focal and generalized dystonia, the pallidal subregion subserving limbic functions (e.g. receiving an input from the NAc) is significantly anterior to the target in dystonia [81].

\section{Ventral Tegmental Area}

Direct modulation of DA output from the VTA has strong theoretical appeal. Targeting small nuclei in highly eloquent areas (such as the midbrain) has been problematic, but recent progress in imaging the VTA [82] as well as in stimulation of the nearby pedunculopontine nucleus for Parkinson disease [83] has made modulatory stimulation a possibility.

Stereotact Funct Neurosurg 2009;87:256-265

\section{Evaluation of the Hypothesis}

Experiments to evaluate this hypothesis need to establish three things: first, that the anterior hippocampus controls DA release into the striatum in normal patients and in patients with schizophrenia. This could be done with neuroimaging studies (especially PET studies with raclopride, fallypride, or other DA radiotracers) on patients from whom the hippocampus has been surgically removed. Second, the effect of hippocampal DBS on DA systems would need to be studied using similar PET scans in patients with implanted hippocampal electrodes, or in nonhuman primates. Finally, our claim that stabilization of DA levels is the most likely explanation for the clinical effects of NAc stimulation needs to be evaluated experimentally. A variety of human, nonhuman primate, and rodent studies using in vivo microdialysis, micro-PET, and other techniques could be designed for this purpose. 


\section{Conclusions}

As neurosurgery for complex behavioral disorders advances, new hope will emerge for the vast population of patients suffering from intractable psychiatric conditions. Advances in systems neuroscience have yielded astonishing levels of insight into the circuitry involved in many disease states, including major depressive disorder, OCD, and schizophrenia. There is no a priori reason that schizophrenia should not join major depressive disorder and OCD as a surgically treatable disease in severe, medication-refractory cases. Research has revealed, perhaps to an even greater extent, how malfunctioning circuits lead to behavioral abnormalities in schizophrenia. In particular, the role of hippocampal control over the DA- ergic system has emerged as a possible target for diagnosis and therapy. However, any novel therapy will be psychiatrist-driven, requiring multidisciplinary cooperation from neurosurgeons, basic scientists, and engineers.

\section{Acknowledgments}

C.B.M. is supported by a Howard Hughes Medical Institute Research Training Fellowship for Medical Students. H.M. is supported by PHS grant P01 NS048120. Solomon Segal is supported by a Paul Janssen Fellowship for Translational Neuroscience. The Neuroresearch Award (Boston Scientific) was given to H.M. and S.S. The authors thank Alexander Sosunov and Zachary Wright for helpful comments. They thank Marianna Shnayderman for aid in the preparation of figures.

\section{References}

1 Tandon R, Keshavan MS, Nasrallah HA: Schizophrenia, 'just the facts' what we know in 2008. 2. Epidemiology and etiology. Schizophr Res 2008;102:1-18.

2 American Psychiatric Association: Diagnostic and Statistical Manual of Mental Disorders, Text Revision. Washington, American Psychiatric Association, 1994, p 298.

-3 Carlsson A, Lindqvist M: Effect of chlorpromazine or haloperidol on formation of 3methoxytyramine and normetanephrine in mouse brain. Acta Pharmacol Toxicol (Copenh) 1963;20:140-144.

4 Laruelle M, Frankle WG, Narendran R, Kegeles LS, Abi-Dargham A: Mechanism of action of antipsychotic drugs: from dopamine $\mathrm{D}(2)$ receptor antagonism to glutamate NMDA facilitation. Clin Ther 2005;27(suppl A):S16-S24.

5 Gray JA, Roth BL: The pipeline and future of drug development in schizophrenia. Mol Psychiatry 2007;12:904-922.

-6 Tandon R, Carpenter WT, Davis JM: Firstand second-generation antipsychotics: learning from CUtLASS and CATIE. Arch Gen Psychiatry 2007;64:977-978.

7 Kapur S, Remington G: Atypical antipsychotics: new directions and new challenges in the treatment of schizophrenia. Annu Rev Med 2001;52:503-517.

-8 Laruelle M, Abi-Dargham A, van Dyck CH, Gil R, D'Souza CD, Erdos J, McCance E, Rosenblatt W, Fingado C, Zoghbi SS, Baldwin RM, Seibyl JP, Krystal JH, Charney DS, Innis RB: Single photon emission computerized tomography imaging of amphetamineinduced dopamine release in drug-free schizophrenic subjects. Proc Natl Acad Sci USA 1996;93:9235-9240.
9 Abi-Dargham A, Gil R, Krystal J, Baldwin RM, Seibyl JP, Bowers M, van Dyck CH, Charney DS, Innis RB, Laruelle M: Increased striatal dopamine transmission in schizophrenia: confirmation in a second cohort. Am J Psychiatry 1998;155:761-767.

10 Abi-Dargham A, Rodenhiser J, Printz D, Zea-Ponce Y, Gil R, Kegeles LS, Weiss R, Cooper TB, Mann JJ, Van Heertum RL, Gorman JM, Laruelle M: Increased baseline occupancy of $\mathrm{D}_{2}$ receptors by dopamine in schizophrenia. Proc Natl Acad Sci USA 2000;97:8104-8109.

11 Frankle WG, Gil R, Hackett E, Mawlawi O, Zea-Ponce Y, Zhu Z, Kochan LD, Cangiano C, Slifstein M, Gorman JM, Laruelle M, AbiDargham A: Occupancy of dopamine $\mathrm{D}_{2}$ receptors by the atypical antipsychotic drugs risperidone and olanzapine: theoretical implications. Psychopharmacology (Berl) 2004; 175:473-480.

12 Kegeles LS, Slifstein M, Frankle WG, Xu X, Hackett E, Bae SA, Gonzales R, Kim JH, Alvarez B, Gil R, Laruelle M, Abi-Dargham A: Dose-occupancy study of striatal and extrastriatal dopamine $\mathrm{D}_{2}$ receptors by aripiprazole in schizophrenia with PET and $\left[{ }^{18} \mathrm{~F}\right]$ fallypride. Neuropsychopharmacology 2008;33:3111-3125.

13 Kapur S: Psychosis as a state of aberrant salience: a framework linking biology, phenomenology, and pharmacology in schizo-

phrenia. Am J Psychiatry 2003;160:13-23.
14 Grace AA, Bunney BS, Moore H, Todd CL: Dopamine-cell depolarization block as a model for the therapeutic actions of antipsychotic drugs. Trends Neurosci 1997;20:31 37.
15 Moore H, Todd CL, Grace AA: Striatal extracellular dopamine levels in rats with haloperidol-induced depolarization block of substantia nigra dopamine neurons. J Neurosci 1998;18:5068-5077.

$\checkmark 16$ Chrapusta SJ, Egan MF: Poor evidence for depolarization block but uncoupling of nigral from striatal dopamine metabolism after chronic haloperidol treatment in the rat. J Neural Transm 2006;113:573-582.

17 Gründer G, Vernaleken I, Müller MJ, Davids E, Heydari N, Buchholz HG, Bartenstein P, Munk OL, Stoeter P, Wong DF, Gjedde A, Cumming P: Subchronic haloperidol downregulates dopamine synthesis capacity in the brain of schizophrenic patients in vivo. Neuropsychopharmacology 2003;28:787-794.

18 Samaha AN, Seeman P, Stewart J, Rajabi H, Kapur S: 'Breakthrough' dopamine supersensitivity during ongoing antipsychotic treatment leads to treatment failure over time. J Neurosci 2007;27:2979-2986.

19 Keefe RS, Bilder RM, Davis SM, Harvey PD, Palmer BW, Gold JM, Meltzer HY, Green MF, Capuano G, Stroup TS, McEvoy JP, Swartz MS, Rosenheck RA, Perkins DO, Davis CE, Hsiao JK, Lieberman JA, CATIE Investigators, Neurocognitive Working Group: Neurocognitive effects of antipsychotic medications in patients with chronic schizophrenia in the CATIE Trial. Arch Gen Psychiatry 2007;64:633-647.

20 Sheitman BB, Lieberman JA: The natural history and pathophysiology of treatment resistant schizophrenia. J Psychiatr Res 1998; 32:143-150

21 Conley RR, Kelly DL: Management of treatment resistance in schizophrenia. Biol Psychiatry 2001;50:898-911. 
22 Palmer BA, Pankratz VS, Bostwick JM: The lifetime risk of suicide in schizophrenia: a reexamination. Arch Gen Psychiatry 2005;62: 247-253.

-23 Neuner T, Schmid R, Wolfersdorf M, Spiessl $\mathrm{H}$ : Predicting inpatient suicides and suicide attempts by using clinical routine data? Gen Hosp Psychiatry 2008;30:324-330.

24 Citrome L: The effectiveness criterion: balancing efficacy against the risks of weight gain. J Clin Psychiatry 2007;68(suppl 12):1217.

25 Mizrahi R, Rusjan P, Agid O, Graff A, Mamo DC, Zipursky RB, Kapur S: Adverse subjective experience with antipsychotics and its relationship to striatal and extrastriatal $\mathrm{D}_{2}$ receptors: a PET study in schizophrenia. Am J Psychiatry 2007;164:630-637.

26 Monroe RR, Heath RG: Studies in Schizophrenia: A Multidisciplinary Approach to Mind-Brain Relationships. Cambridge, Harvard University Press, 1955, pp 345-389.

-27 Ressler KJ, Mayberg HS: Targeting abnormal neural circuits in mood and anxiety disorders: from the laboratory to the clinic. Nat Neurosci 2007; 10:1116-1124.

28 Nuttin B, Cosyns P, Demeulemeester H, Gybels J, Meyerson B: Electrical stimulation in anterior limbs of internal capsules in patients with obsessive-compulsive disorder. Lancet 1999;354:1526.

-29 Mayberg HS, Lozano AM, Voon V, McNeely HE, Seminowicz D, Hamani C, Schwalb JM, Kennedy SH: Deep brain stimulation for treatment-resistant depression. Neuron 2005;45:651-660.

- 30 Rauch SL, Dougherty DD, Malone D, Rezai A, Friehs G, Fischman AJ, Alpert NM, Haber SN, Stypulkowski PH, Rise MT, Rasmussen SA, Greenberg BD: A functional neuroimaging investigation of deep brain stimulation in patients with obsessive-compulsive disorder. J Neurosurg 2006;104:558-565.

- 31 Greenberg BD, Malone DA, Friehs GM, Rezai AR, Kubu CS, Malloy PF, Salloway SP, Okun MS, Goodman WK, Rasmussen SA: Three-year outcomes in deep brain stimulation for highly resistant obsessive-compulsive disorder. Neuropsychopharmacology 2006;31:2384-2393.

- 32 Maciunas RJ, Maddux BN, Riley DE, Whitney CM, Schoenberg MR, Ogrocki PJ, Albert JM, Gould DJ: Prospective randomized double-blind trial of bilateral thalamic deep brain stimulation in adults with Tourette syndrome. J Neurosurg 2007;107:10041014.

33 Welter ML, Mallet L, Houeto JL, Karachi C, Czernecki V, Cornu P, Navarro S, Pidoux B, Dormont D, Bardinet E, Yelnik J, Damier P, Agid Y: Internal pallidal and thalamic stimulation in patients with Tourette syndrome. Arch Neurol 2008;65:952-957.

34 El-Hai J: The Lobotomist: A Maverick Medical Genius and His Tragic Quest to Rid the World of Mental Illness. Hoboken, Wiley, 2005 .
35 Kegeles L, Frankle W, Gil R, Narendran R, Slifstein M, Hwang D-R, Cangiano C, Haber S, Abi-Dargham A, Laruelle M: Schizophrenia is associated with increased synaptic dopamine in associative rather than limbic regions of the striatum: implications for mechanisms of action of antipsychotic drugs. J Nucl Med 2006;47(suppl 1):139P.

36 Schultz W: Multiple dopamine functions at different time courses. Annu Rev Neurosci 2007;30:259-288.

37 Salamone JD, Correa M, Mingote SM, Weber SM: Beyond the reward hypothesis: alternative functions of NAc dopamine. Curr Opin Pharmacol 2005;5:34-41.

38 Hollerman JR, Schultz W: Dopamine neurons report an error in the temporal prediction of reward during learning. Nat Neurosci 1998;1:304-309.

39 Goto Y, Otani S, Grace AA: The Yin and Yang of dopamine release: a new perspective. Neuropharmacology 2007;53:583-587.

40 Grace AA, Floresco SB, Goto Y, Lodge DJ: Regulation of firing of dopaminergic neurons and control of goal-directed behaviors. Trends Neurosci 2007;30:220-227.

41 Goto Y, Grace AA: The dopamine system and the pathophysiology of schizophrenia: a basic science perspective. Int Rev Neurobiol 2007;78C:41-68.

42 Legault M, Wise RA: Novelty-evoked elevations of nucleus accumbens dopamine: dependence on impulse flow from the ventral subiculum and glutamatergic neurotransmission in the ventral tegmental area. Eur J Neurosci 2001:13:819-828.

43 Lisman JE, Grace AA: The hippocampalVTA loop: controlling the entry of information into long-term memory. Neuron 2005; 46:703-713.

44 Grace AA, Floresco SB, Goto Y, Lodge DJ: Regulation of firing of dopaminergic neurons and control of goal-directed behaviors. Trends Neurosci 2007;30:220-227.

45 Lawrie SM, Abukmeil SS: Brain abnormality in schizophrenia: a systematic and quantitative review of volumetric magnetic resonance imaging studies. Br J Psychiatry 1998; 172:110-120.

46 Nelson MD, Saykin AJ, Flashman LA, Riordan HJ: Hippocampal volume reduction in schizophrenia as assessed by magnetic resonance imaging: a meta-analytic study. Arch Gen Psychiatry 1998;55:433-440.

47 Velakoulis D, Wood SJ, Wong MT, McGorry PD, Yung A, Phillips L, Smith D, Brewer W, Proffitt T, Desmond P, Pantelis C: Hippocampal and amygdala volumes according to psychosis stage and diagnosis: a magnetic resonance imaging study of chronic schizophrenia, first-episode psychosis, and ultrahigh-risk individuals. Arch Gen Psychiatry 2006;63:139-149.
48 Gothelf D, Soreni N, Nachman RP, Tyano S, Hiss Y, Reiner O, Weizman A: Evidence for the involvement of the hippocampus in the pathophysiology of schizophrenia. Eur Neuropsychopharmacol 2000;10:389-395.

49 Achim AM, Bertrand MC, Sutton H, Montoya A, Czechowska Y, Malla AK, Joober R, Pruessner JC, Lepage M: Selective abnormal modulation of hippocampal activity during memory formation in first-episode psychosis. Arch Gen Psychiatry 2007;64:999-1014.

50 Lahti AC, Weiler MA, Holcomb HH, Tamminga CA, Carpenter WT, McMahon R: Correlations between rCBF and symptoms in two independent cohorts of drug-free patients with schizophrenia. Neuropsychopharmacology 2006;31:221-230.

51 Duncan JS: Imaging and epilepsy. Brain 1997;120:339-377.

52 Knowlton RC, Laxer KD, Klein G, Sawrie S, Ende G, Hawkins RA, Aassar OS, Soohoo K, Wong S, Barbaro N: In vivo hippocampal glucose metabolism in mesial temporal lobe epilepsy. Neurology 2001;57:1184-1190.

53 Schobel SA, Lewandowski NM, Corcoran C, Pereira AC, Moore H, Tang M, Kimhy D, Brown T, Malaspina D, Small SA: The CA1 subfield is a dominant site of hippocampal hyperfunction in schizophrenia. Arch General Psychiatry, in press.

54 Moore H, Jentsch JD, Ghajarnia M, Geyer MA, Grace AA: A neurobehavioral systems analysis of adult rats exposed to methylazoxymethanol acetate on E17: implications for the neuropathology of schizophrenia. Biol Psychiatry 2006;60:253-264.

55 Lodge DJ, Grace AA: Aberrant hippocampal activity underlies the dopamine dysregulation in an animal model of schizophrenia. J Neurosci 2007;27:11424-11430.

56 Velasco M, Velasco F, Velasco AL: Centromedian-thalamic and hippocampal electrical stimulation for the control of intractable epileptic seizures. J Clin Neurophysiol 2001; 18:495-513.

57 Vonck K, Boon P, Achten E, De Reuck J, Caemaert J: Long-term amygdalohippocampal stimulation for refractory temporal lobe epilepsy. Ann Neurol 2002;52:556-565.

58 Boon P, Vonck K, De Herdt V, Van Dycke A, Goethals M, Goossens L, Van Zandijcke M, De Smedt T, Dewaele I, Achten R, Wadman W, Dewaele F, Caemaert J, Van Roost D: Deep brain stimulation in patients with refractory temporal lobe epilepsy. Epilepsia 2007;48:1551-1560.

59 Velasco AL, Velasco F, Velasco M, Trejo D, Castro G, Carrillo-Ruiz JD: Electrical stimulation of the hippocampal epileptic foci for seizure control: a double-blind, long-term follow-up study. Epilepsia 2007;48:18951903.

60 Lian J, Bikson M, Sciortino C, Stacey WC, Durand DM: Local suppression of epileptiform activity by electrical stimulation in rat hippocampus in vitro. J Physiol 2003;547: 427-434. 
61 Durand DM, Jensen A, Bikson M: Suppression of neural activity with high frequency stimulation. Conf Proc IEEE Eng Med Biol Soc 2006; 1:1624-1625.

62 Jensen AL, Durand DM: Suppression of axonal conduction by sinusoidal stimulation in rat hippocampus in vitro. J Neural Eng 2007; 4:1-16.

63 Wyckhuys T, De Smedt T, Claeys P, Raedt R, Waterschoot L, Vonck K, Van den Broecke C, Mabilde C, Leybaert L, Wadman W, Boon P: High frequency deep brain stimulation in the hippocampus modifies seizure characteristics in kindled rats. Epilepsia 2007;48: 1543-1550.

64 Joel D, Weiner I: The connections of the dopaminergic system with the striatum in rats and primates: an analysis with respect to the functional and compartmental organization of the striatum. Neuroscience 2000;96:451474.

65 Haber SN, Fudge JL, McFarland NR: Striatonigrostriatal pathways in primates form an ascending spiral from the shell to the dorsolateral striatum. J Neurosci 2000;20:23692382.

66 Ikemoto S: Dopamine reward circuitry: two projection systems from the ventral midbrain to the nucleus accumbens-olfactory tubercle complex. Brain Res Rev 2007;56:2778.

67 Perlstein WM, Carter CS, Noll DC, Cohen JD: Relation of prefrontal cortex dysfunction to working memory and symptoms in schizophrenia. Am J Psychiatry 2001;158:11051113.

68 Kellendonk C, Simpson EH, Polan HJ, Malleret G, Vronskaya S, Winiger V, Moore H, Kandel ER: Transient and selective overexpression of dopamine $\mathrm{D}_{2}$ receptors in the striatum causes persistent abnormalities in prefrontal cortex functioning. Neuron 2006; 49:603-615.
69 Greenberg BD, Gabriels LA, Malone DA Jr, Rezai AR, Friehs GM, Okun MS, Shapira NA, Foote KD, Cosyns PR, Kubu CS, Malloy PF, Salloway SP, Giftakis JE, Rise MT, Machado AG, Baker KB, Stypulkowski $\mathrm{PH}$, Goodman WK, Rasmussen SA, Nuttin BJ Deep brain stimulation of the ventral internal capsule/ventral striatum for obsessivecompulsive disorder: worldwide experience. Mol Psychiatry 2008, E-pub ahead of print.

70 Kuhn J, Lenartz D, Mai JK, Huff W, Lee SH, Koulousakis A, Klosterkoetter J, Sturm V: Deep brain stimulation of the nucleus accumbens and the internal capsule in therapeutically refractory Tourette-syndrome. J Neurol 2007;254:963-965.

71 Schlaepfer TE, Cohen MX, Frick C, Kosel M, Brodesser D, Axmacher N, Joe AY, Kreft M, Lenartz D, Sturm V: Deep brain stimulation to reward circuitry alleviates anhedonia in refractory major depression. Neuropsychopharmacology 2008;33:368-377.

72 Malone DA Jr, Dougherty DD, Rezai AR, Carpenter LL, Friehs GM, Eskandar EN, Rauch SL, Rasmussen SA, Machado AG, Kubu CS, Tyrka AR, Price LH, Stypulkowski PH, Giftakis JE, Rise MT, Malloy PF, Salloway SP, Greenberg BD: Deep brain stimulation of the ventral capsule/ventral striatum for treatment-resistant depression. Biol Psychiatry 2009;65:267-275.

73 Vassoler FM, Schmidt HD, Gerard ME, Famous KR, Ciraulo DA, Kornetsky C, Knapp CM, Pierce RC: Deep brain stimulation of the nucleus accumbens shell attenuates cocaine priming-induced reinstatement of drug seeking in rats. J Neurosci 2008;28: 8735-8739.

74 Liu HY, Jin J, Tang JS, Sun WX, Jia H, Yang XP, Cui JM, Wang CG: Chronic deep brain stimulation in the rat nucleus accumbens and its effect on morphine reinforcement. Addict Biol 2008;13:40-46.

75 Benabid AL, Pollak P, Gervason C, Hoffmann D, Gao DM, Hommel M, Perret JE, de Rougemont J: Long-term suppression of tremor by chronic stimulation of the ventral intermediate thalamic nucleus. Lancet 1991 337:403-406.
76 Hamamura T, Harada T: Unique pharmacological profile of aripiprazole as the phasic component buster. Psychopharmacology (Berl) 2007;191:741-743.

77 Grace AA: Phasic versus tonic dopamine release and the modulation of dopamine system responsivity: a hypothesis for the etiology of schizophrenia. Neuroscience 1991;41: $1-24$.

78 Breitenstein C, Korsukewitz C, Flöel A, Kretzschmar T, Diederich K, Knecht S: Tonic dopaminergic stimulation impairs associative learning in healthy subjects. Neuropsychopharmacology 2006;31:2552-2564.

79 Floresco SB, Todd CL, Grace AA: Glutamatergic afferents from the hippocampus to the nucleus accumbens regulate activity of ventral tegmental area dopamine neurons. J Neurosci 2001;21:4915-4922.

-80 Plewnia C, Schober F, Rilk A, Buchkremer G, Reimold M, Wächter T, Breit S, Weiss D, Krüger R, Freudenstein D: Sustained improvement of obsessive-compulsive disorder by deep brain stimulation in a woman with residual schizophrenia. Int J Neuropsychopharmacol 2008;11:1181-1183.

-81 Haber SN, Kunishio K, Mizobuchi M, LyndBalta E: The orbital and medial prefrontal circuit through the primate basal ganglia. J Neurosci 1995;15:4851-4867.

-82 D’Ardenne K, McClure SM, Nystrom LE, Cohen JD: BOLD responses reflecting dopaminergic signals in the human ventral tegmental area. Science 2008;319:1264-1267.

83 Stefani A, Lozano AM, Peppe A, Stanzione P, Galati S, Tropepi D, Pierantozzi M, Brusa L, Scarnati E, Mazzone P: Bilateral deep brain stimulation of the pedunculopontine and subthalamic nuclei in severe Parkinson's disease. Brain 2007;130:1596-1607.

84 Martin JH: Neuroanatomy: Text and Atlas. New York, McGraw-Hill Medical, 2003 